\title{
Pain Maps from Facial Pain Patients Indicate a Broad Pain Geography
}

\author{
J.C. Türp ${ }^{1}$, C.J. Kowalski ${ }^{1,2}$, N. $\mathrm{O}^{\prime}$ Leary $^{1}$, and C.S. Stohler ${ }^{1,3 *}$
}

\begin{abstract}
${ }^{1}$ Department of Biologic and Materials Sciences, School of Dentistry; ${ }^{2}$ Center for Statistical Consultation and Research; and ${ }^{3}$ Center for Human Growth and Development, The University of Michigan, Ann Arbor, Michigan 48109-1078, USA; *to whom correspondence and reprint requests should be addressed
\end{abstract}

\begin{abstract}
Two hundred consecutive female patients, who were referred to a university-based facial pain clinic, were asked to mark all painful sites on sketches showing the contours of a human body in the frontal and rear views. The drawings were analyzed with transparent templates containing 1875 (frontal view) and 1929 (rear view) square cells of equal size. The average patient scored 71.8 cells in the frontal and 99.7 cells in the rear view (corresponding to $3.8 \%$ and $5.2 \%$ of the maximum possible scores). In individual patient drawings, however, up to $42.7 \%$ and $44.9 \%$ of all cells were marked. Only 37 cases $(18.5 \%)$ exhibited pain that was limited to the trigeminal system. An analysis of the pain distribution according to the arrangements of dermatomes revealed three distinct clusters of patients: (1) pain restricted to the region innervated by the trigeminal nerves $(n=37)$; $(2)$ pain in the trigeminal dermatomes and any combination involving the spinal dermatomes $\mathrm{C} 2, \mathrm{C} 3$, and $\mathrm{C} 4$, but no other dermatomes ( $\mathrm{n}=32)$; and (3) pain sites involving dermatomes in addition to the ones listed above $(n=131)$. Mean ages in the three clusters were $38.7,35.5$, and 37.5 years, respectively ( $p=0.62$, n.s.). Widespread pain existed for longer durations (median, 48 months) than conditions involving local and regional pain (median, 24 months) $(p=0.02, s$.). Our findings showed that among a great percentage of persistent facial pain patients the pain distribution is more widespread than commonly assumed, and that the persistence of pain in the regional and widespread pain presentations is significantly greater than in cases with pain limited to the trigeminal system.
\end{abstract}

Key words: chronic pain, musculoskeletal pain, pain drawings, pain distribution, dermatomes.

Received February 27, 1997; Last Revision August 21, 1997; Accepted September 29, 1997

\section{Introduction}

Since their introduction into the medical literature a few decades ago (Keele, 1948; Palmer, 1949), patient-made paperand-pencil drawings, which are sometimes referred to as "pain charts" (Palmer, 1949) or "pain maps" (Cummings and Routan, 1987), have been widely applied in the evaluation of pain patients. Using this tool, patients receive line drawings of the human body or parts thereof, and they are asked to mark the location and distribution of their pain(s). High intra- and interobserver agreement (Ohnmeiss et al., 1995; Parker et al., 1995) and a good test-retest reliability (Margolis et al., 1988) have been established for these instruments.

Patient-produced pain drawings have often been used in studies of low back pain (Ransford et al., 1976; Mann et al., 1993; Takata and Hirotani, 1995; Sikorski et al., 1996). Less frequently, they have been used in investigations of other conditions, such as migraine headaches (Russell et al., 1994), fibromyalgia (Wigers et al., 1996), chronic neck pain (Sandmark and Nisell, 1994), and post-surgical pain (Sanderson and Wood, 1993; Vucetic et al., 1995). In addition, pain drawings have served as predictors of treatment outcome (McNeill et al., 1986; Watters et al., 1989). Only rarely have these instruments been used for the assessment of persistent facial pain (PFP) patients (Gray et al., 1986; Hagberg, 1991; Allerbring and Hægerstam, 1993; Damon et al., 1994; Hagberg et al., 1994; Bertoft, 1996). This is somewhat surprising, because such drawings have been found useful for diagnostic, therapeutic, prognostic, and research purposes (Jensen and Karoly, 1992; Margoles, 1983).

Emerging evidence suggests a significant overlap between temporomandibular disorder states and pain conditions in other parts of the body (Blasberg and Chalmers, 1989; Krause et al., 1989; Hagberg, 1991; Krogstad et al., 1992; Allerbring and Hægerstam, 1993; Hagberg et al., 1994). To increase our understanding of the extent to which musculoskeletal pain in the face is paralleled by pain outside the face, we systematically analyzed the bodily pain presentations of patients suffering from persistent musculoskeletal facial pain. We hypothesized that, in a considerable number of cases, pain complaints involve 

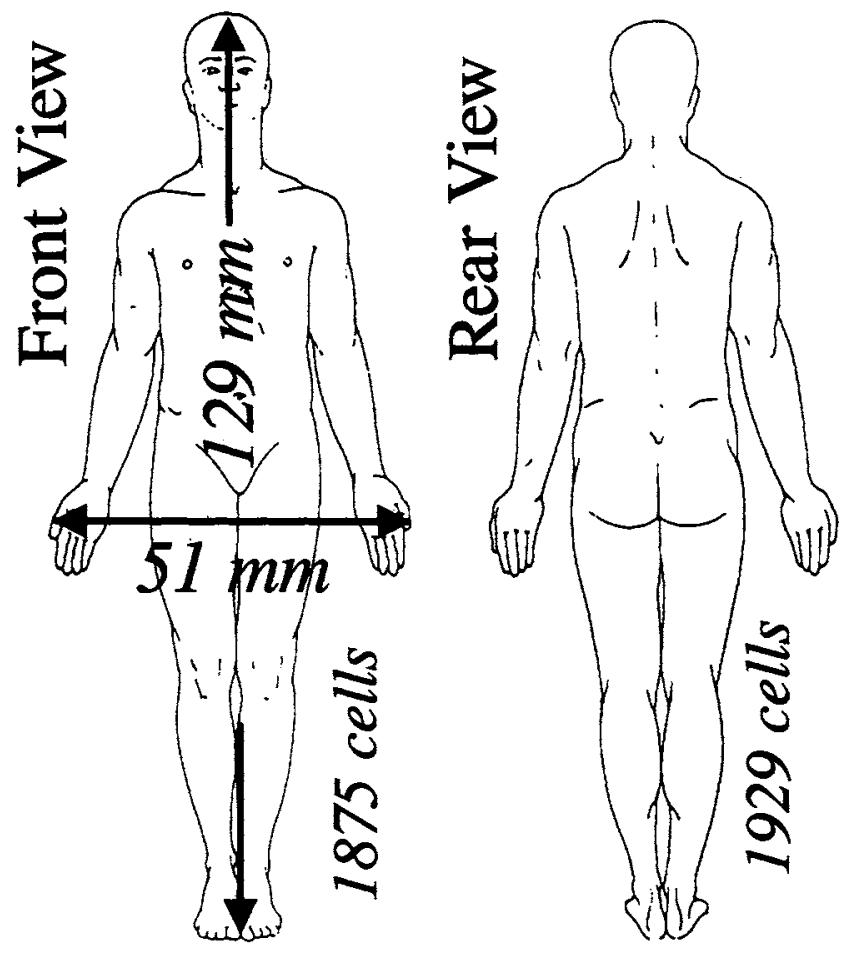

Figure 1. Outline and dimensions of the sketches of the human body.

regions well beyond the head and face, and that distinct clusters of particular forms of spatial pain distributions can be identified. With this project, we intended to provide answers to the following five questions:

(1) What is the extent of self-reported pain in PFP patients?

(2) Are the pain sites more often confined to one side of the body (unilateral), or is a bilateral distribution more common?

(3) Which anatomical regions outside the head/face area are most likely to be affected?

(4) How does the pain distribution relate to the dermatomes?

(5) Does a pattern of spreading or radiating pain on drawings correspond with the selection of specific adjectives on the McGill Pain Questionnaire (MGPQ) (Melzack, 1975)?

\section{Materials and methods}

The study was based on data from 200 consecutive female patients who were referred to a university-based multidisciplinary tertiary care clinic for the diagnosis and management of persistent musculoskeletal facial pain. The patients' mean age was 37.4 yrs (SD, 13.5; min, 15 yrs; max, 74 yrs). The sample included $91.5 \%$ Americans of European descent, $2 \%$ African-Americans, 2\% Asian-Americans, and 1\% Native Americans; $3.5 \%$ of the patients belonged to other ethnic groups. Fifty-seven percent of the individuals were married, $29.7 \%$ single (never married), $7.2 \%$ divorced, $2.1 \%$ separated, and $2.1 \%$ widowed $(n=195)$. Patients were in pain for a mean duration of $79.2 \operatorname{mos}(\mathrm{SD}, 95.2 ; \min , 1 \mathrm{mo} ; \max , 588 \operatorname{mos} ; \mathrm{n}=$ 190), and were seen by an average of 4.5 treatment providers (SD, 4.1) prior to being referred to our clinic. The study was approved by the institutional review board for the use of human subjects.

Each individual was asked to indicate painful body sites on sketches of the human body in the frontal and rear views. The sketches were $129 \mathrm{~mm}$ high (head to toe) and $51 \mathrm{~mm}$ broad (thumb to thumb; Fig. 1). Patients were instructed to mark with arrows the spread of pain, and to shade all the areas that were painful. A dot was used for focal pain involvement. Two pain drawings were provided as examples.

The patients' drawings were analyzed by one examiner with the help of two transparent templates. For the first four analyses, a grid of 20 squares to the inch was used. In total, the frontal view of the body outline contained 1875 squares (cells), whereas the view from the rear was composed of 1929 squares. Coordinates were allocated to each cell.

\section{Assessment of overall pain distribution}

Whenever a part of the patient's drawing touched a square on the template, this cell was scored as positive. The intrarater reliability of the procedure was assessed by re-measurement of 20 randomly chosen pain drawings ( $10 \%$ of the total sample). The Intraclass Correlation Coefficient (ICC) was computed. The ICC was essentially 1.0 (rounded from the exact value of 0.99 ).

\section{Assessment of pain spread and laterality}

We then determined in how many patients the pain was confined to the head and face, and how often additional parts of the body were involved. Whenever squares outside the head and face were part of the drawing, we counted the pain as not being limited to the head and face. We also divided each of the frontal and rear body outlines into a right and a left half for the purpose of counting the number of patients who had a unilateral as opposed to a bilateral distribution of pain.

\section{Specific pain sites}

Specific sites-namely, the upper part of the head, the face, neck, neck and shoulders, and knees for the frontal diagram, and the head, neck, upper back, middle back, lower back, and knees for the dorsal view-were of interest in this analysis. In the frontal view, for example, the upper part of the head consisted of 47 , the face 66 , and the knees 70 cells. For each of these anatomical regions, the average score, the percentage of the average score relative to the maximum possible score, the maximum individual score, and the percentage of this score relative to the maximum possible score were calculated. Furthermore, we determined for each site the percentage of patients whose drawings included $0,>0$ to $20 \%,>20$ to $50 \%$, and $>50 \%$ of all possible squares.

\section{Pain distribution within dermatomes}

A clear plastic sheet with the segmental arrangements of human dermatomes in the frontal and rear views was used for this part of the analysis. In addition to the head/face area (HF), 7 cervical 
(C2 to C8), 12 thoracic (T1 to T12), 5 lumbar (L1 to L5), and 4 sacral (S1 to $\mathrm{S4}$ ) dermatomes were distinguished. When a part of the drawing lay within a spinal dermatome (or the head/face area), this specific dermatome was counted. The individual as well as the overall distributions of dermatome involvement (dermatome-total, dermatome-cervical, dermatome-thoracic, dermatome-lumbar, dermatome-sacral) were computed. In addition, the dermatome involvement of each patient was graphically displayed. The individual pain distributions were then subjected to a cluster analysis.

\section{Radiating and spreading pain}

For the final analysis, the pain drawings were inspected visually. The presence of at least one solid dot or one shaded area with a diameter of $4 \mathrm{~mm}$ or more, or of a dotted or solid line with or without arrows was considered to be spreading or radiating pain. In contrast, drawings showing dots smaller than $4 \mathrm{~mm}$ in diameter or " $\mathrm{x}$ "-like marks were not counted as "spreading or radiating pain". Every patient filled out the MGPQ. For the purpose of this study, we considered only MGPQ word group number 17, which is part of the miscellaneous subclass of this questionnaire and includes the sensory pain descriptors "spreading", "radiating", "penetrating", and "piercing". After examining which patients selected words from this group, we determined the correspondence between spreading or radiating pain on the pain drawings and choosing the corresponding words on the MGPQ.

\section{Results}

\section{Overall pain distribution}

The total number of cells included in patients' drawings ranged between 0 and 801 (maximum possible score, 1875) in the frontal view, and between 0 and 866 (maximum possible
Table 1. Table showing the number of patients with a specific combination of laterality and pain extent $(n=200)$

\begin{tabular}{lccc}
\hline & $\begin{array}{c}\text { Pain Limited to } \\
\text { Head and Face }\end{array}$ & $\begin{array}{c}\text { Pain Extending Beyond } \\
\text { Head and Face }\end{array}$ & Totals \\
\hline Unilateral Pain & 21 & 14 & 35 \\
Bilateral Pain & 41 & 124 & 165 \\
\hline Totals & 62 & 138 & 200 \\
\hline
\end{tabular}

score, 1929) in the rear view. Thus, up to $42.7 \%$ and $44.9 \%$ of all squares were marked in individual patient drawings. The average patient scored 71.8 cells in the front view and 99.7 cells in the rear view, which correspond to $3.8 \%$ and $5.2 \%$ of the maximum scores. The patterns of the distribution of cells in the frontal and rear views are shown in Figs. $2 a$ and $2 b$. The display reveals that the cells most often involved are located in the head and face. The central part of the face (eyes, nose), however, was seldom included. In the frontal view, the square that was most often part of a drawing was involved 118 times, and 16 out of the 20 cells most frequently marked in the 200 drawings were located within the face. In the rear view, no cell was chosen more often than 79 times; interestingly, 19 out of the 20 most frequently involved cells were located in the neck area. Only 82 out of the 1875 cells related to the frontal view were not part of any drawing, as opposed to 141 out of 1929 in the rear view.

\section{Pain spread and laterality}

Bilateral pain was reported by $82.5 \%$ of subjects. In $69 \%$ of patients, pain extended to regions outside the head and face. The distribution of painful sites as (a) unilateral or bilateral, and (b) limited to the head and face or extending beyond this anatomical region is summarized in Table 1. Among the

Table 2. Involvement of specific pain sites using the grid approach

\begin{tabular}{|c|c|c|c|c|c|c|}
\hline & $\begin{array}{l}\text { Number of } \\
\text { Involved } \\
\text { Squares }^{a}\end{array}$ & $\begin{array}{l}\text { Average Score/ } \\
\text { Maximum } \\
\text { Observed Score }\end{array}$ & $0 \%$ & $>0-20 \%$ & $>20-50 \%$ & $>50-100 \%$ \\
\hline \multicolumn{7}{|l|}{ Frontal View } \\
\hline Upper head & 47 & $8.7 / 47$ & 46.0 & 23.0 & 18.5 & 12.5 \\
\hline Face mask & 66 & $14.9 / 66$ & 4.5 & 54.0 & 35.0 & 6.5 \\
\hline Neck & 38 & $7.2 / 38$ & 33.0 & 30.0 & 25.5 & 11.5 \\
\hline Neck/shoulder & 79 & $12.6 / 79$ & 31.0 & 37.0 & 23.0 & 9.0 \\
\hline Knees & 70 & $2.6 / 68$ & 87.0 & 7.5 & 3.0 & 2.5 \\
\hline \multicolumn{7}{|l|}{ Rear View } \\
\hline Head & 105 & $14.4 / 105$ & 43.5 & 35.5 & 14.0 & 7.0 \\
\hline Neck & 32 & $10.6 / 32$ & 38.0 & 9.0 & 26.0 & 27.0 \\
\hline Upper back & 225 & $32.1 / 225$ & 41.0 & 32.5 & 19.0 & 7.5 \\
\hline Middle back & 207 & $10.0 / 204$ & 68.5 & 25.5 & 4.0 & 2.0 \\
\hline Lower back & 142 & $8.5 / 104$ & 70.0 & 18.0 & 9.5 & 2.5 \\
\hline Knees & 54 & $1.5 / 54$ & 90.5 & 5.5 & 2.0 & 2.0 \\
\hline
\end{tabular}

a Number of squares included in the specific body area, average and maximum individual patient scores of specific pain sites, and percentage of patients in whose drawing $0,>0-20 \%,>20-50 \%$, and $>50 \%$ of all cells were included in the particular body area. 

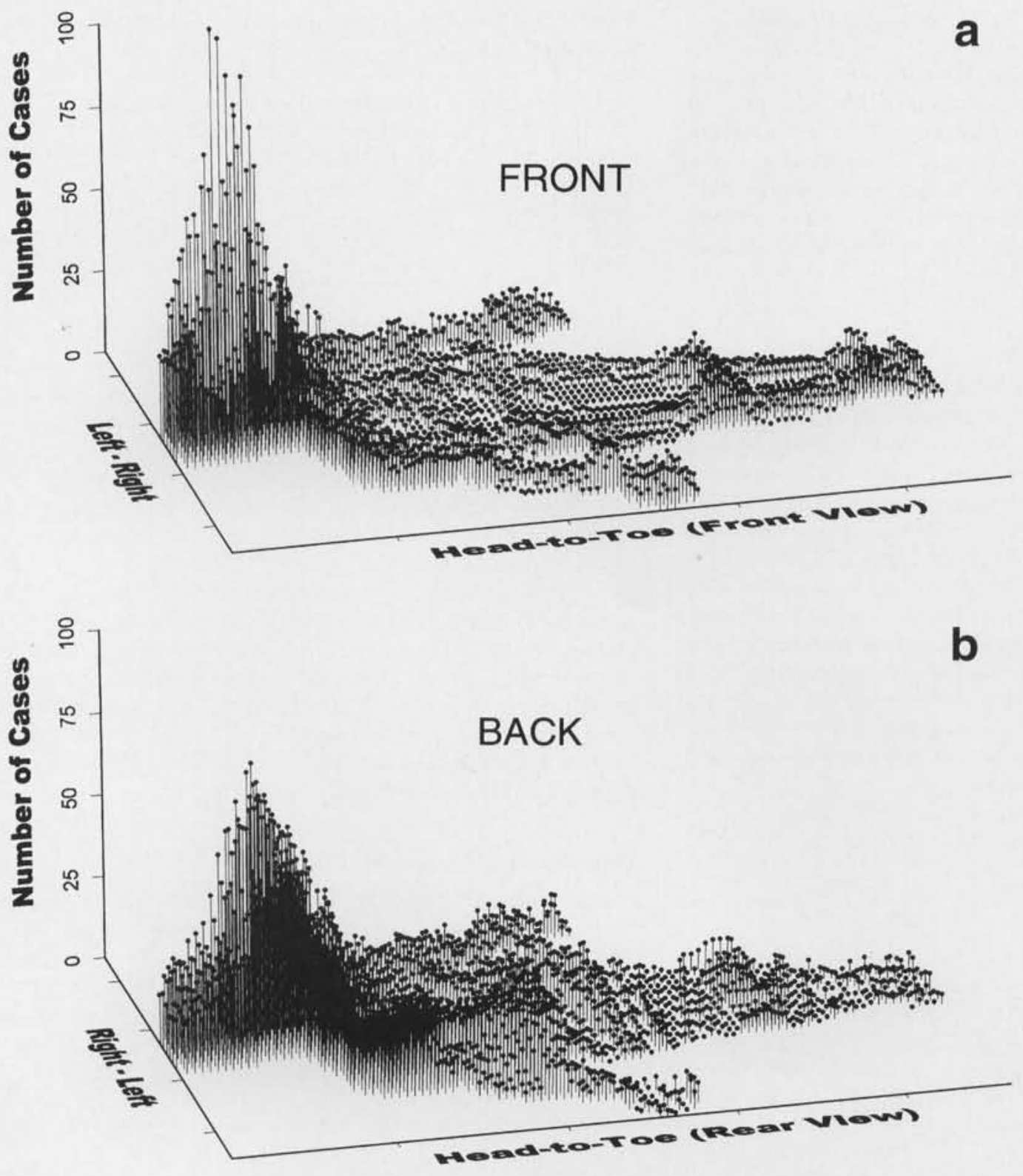

Figure 2. Three-dimensional graphical distribution of the reporting frequency of the cells $(n=200)$. The vertical axis in the three-dimensional diagram refers to the number of patients. (a) Frontal view. (b) Rear view.

21 patients with unilateral head/face pain, 11 experienced pain on the left side, nine on the right side, and one in the central portion of the face. Among the individuals with unilateral pain beyond the head/face region, the pain was limited to the left and right sides in seven subjects each.

\section{Specific pain sites}

In addition to the face/head area, certain body regions showed a high frequency of pain reports. In the frontal view, these areas included the neck and shoulder regions (Fig. 2a). The upper arm and knees were involved to a lesser degree. Frequencies on posterior body diagrams were particularly high in the head, neck, and upper back region, followed by the middle and lower back regions (Fig. 2b). The lower half of the body showed a relatively low level of pain. Table 2 presents the average and maximum values by body region. In each region except the knees and the lower back, some individuals included every square in that region. Table 2 also gives, by body areas, the percentages of patients showing no cells, between $1 \%$ and $20 \%$, between more than $20 \%$ and $50 \%$, and more than $50 \%$. Not surprisingly, pain in the face was almost always present. The nine patients who did not include this region in their drawings indicated pain sites in the head area (besides possible additional pain sites outside the head or face).

\section{Pain distribution within dermatomes}

Table 3 gives the distribution of the involvement of dermatomes in the pain drawings. Trigeminal dermatomes were involved in $95.5 \%$ of drawings. The remaining $4.5 \%$ of the patients $(\mathrm{n}=9)$ marked pain sites within the $\mathrm{C} 2$ or C3 dermatomes. These two dermatomes cover a small part of the frontal view (neck, including the corners of the mandible) and a relatively large area of the rear view (head). Every dermatome was selected by at least one patient. Examination of pain profiles revealed three distinct subgroups (or clusters) of patients. Denoted by G1, G2, and G3, the clusters could be described as:

- $\mathrm{G} 1(\mathrm{n}=37)$ : pain restricted to the region innervated by the trigeminal nerves;

- $\mathrm{G} 2(\mathrm{n}=32)$ : pain in the trigeminal dermatomes and any combination involving the spinal dermatomes $\mathrm{C} 2, \mathrm{C} 3$, and C4, but no other dermatomes; and 
- G3 ( $n=131)$ : pain sites involving dermatomes in addition to the ones listed in $\mathrm{G} 2$.

Drawings of typical cluster members G1, G2, and G3 (including the G3 member with the most widespread pain involvement [G3']) are shown in Fig. 3. The mean ages of the members of the three clusters G1, G2, and G3 were 38.7, 35.5 , and 37.5 yrs, respectively. These differences were not different to any statistically significant degree (one-way analysis of variance: $p=0.62$, n.s.). The Kruskal-Wallis test revealed a borderline significance $(p=0.0507)$ regarding pain persistence in the three clusters. When clusters G1 and G2 were combined and compared with G3 by the MannWhitney $U$ test, a statistically significant difference in the persistence of pain between the local (G1) to regional (G2) and widespread presentations (G3) was found ( $p=0.023, s)$. Median time in pain was 24 mos for clusters G1 and G2, and 48 mos for $G 3$.

\section{Radiating and spreading pain}

The results of the comparison of the MGPQ word selection and the drawings are presented in Table 4. Seventy-seven out of the 167 patients whose drawings were indicative of spreading/radiating pain chose the corresponding words on the MGPQ, and 45 additional patients selected one of the other two verbal pain descriptors in this group. Forty-five patients with spreading/radiating pain in the drawings did not choose any word in MGPQ group 17, whereas 11 out of 33 patients without spreading/radiating pain in the drawings selected a word from this MGPQ group, two of them "spreading" or "radiating".

\section{Discussion}

The clinically most important finding of this investigation is that a vast majority of our sample-more than two-thirdsreported pain in the head and face, and pain outside this area. In some patients, more than $40 \%$ of the total sum of 3804 cells were part of the drawing. Often, heterotopic pain sites were marked in the drawings.

Although it has been reported that pain complaints of PFP patients are not necessarily confined to the face, earlier studies were based on a limited number of patients (e.g., Eriksson et al., 1988), or focused primarily on the concomitant presence of headaches (e.g., Costen, 1934; Gelb and Tarte, 1975; Magnusson and Carlsson, 1978a,b; Solberg et al., 1979; Schokker et al., 1990; Wänman and Agerberg, 1986). Only relatively few articles have shown that PFP patients may have a widespread pain distribution throughout the rest of the body (Berry, 1969; Heiberg et al., 1978; Blasberg and Chalmers, 1989; Krause et al., 1989; Hagberg, 1991; Krogstad et al., 1992; Allerbring and Hægerstam, 1993; Hagberg et al., 1994).

Allerbring and Hægerstam (1993), who examined patient-produced pain drawings (frontal and rear views) of 49 individuals suffering from "chronic idiopathic orofacial pain", used methodology similar to ours. Interestingly, 35 of their patients $(71 \%)$ reported pain outside the face, which is about the same as in our study (69\%). Another investigation relied on pain reports of 80 patients (56 women, mean age 42
Table 3. Number and percentage of pain patients who included particular dermatomes in their drawing

\begin{tabular}{lcc}
\hline Dermatome & Number of Cases & Percent of Cases \\
\hline Trigeminal and & Cervical Dermatomes & \\
Trigeminal & 191 & 95.5 \\
C2 $^{\mathrm{a}}$ & 120 & 60.0 \\
C3 & 112 & 56.0 \\
C4 & 119 & 59.5 \\
C5 & 110 & 55.0 \\
C6 & 110 & 55.0 \\
C7 & 95 & 47.5 \\
C8 & 77 & 38.5
\end{tabular}

$\begin{array}{lll}\text { Thoracic Dermatomes } & & \\ \text { T1 } & 68 & 34.0 \\ \text { T2 } & 58 & 29.0 \\ \text { T3 } & 55 & 27.5 \\ \text { T4 } & 58 & 29.0 \\ \text { T5 } & 45 & 22.5 \\ \text { T6 } & 40 & 20.0 \\ \text { T7 } & 38 & 19.0 \\ \text { T8 } & 33 & 16.5 \\ \text { T9 } & 31 & 15.5 \\ \text { T10 } & 33 & 16.5 \\ \text { T11 } & 33 & 16.5 \\ \text { T12 } & 40 & 20.0\end{array}$

$\begin{array}{lll}\text { Lumbar Dermatomes } & & \\ \text { L1 } & 45 & 22.5 \\ \text { L2 } & 46 & 23.0 \\ \text { L3 } & 47 & 23.5 \\ \text { L4 } & 52 & 26.0 \\ \text { L5 } & 47 & 23.5\end{array}$

\begin{tabular}{lrc} 
Sacral Dermatomes & & \\
S1 & 40 & 20.0 \\
S2 & 22 & 11.0 \\
S3 & 5 & 2.5 \\
S4 & 3 & 1.5 \\
\hline a & C = Cervical, T = Thoracic, L = Lumbar, and S = Sacral \\
& dermatomes.
\end{tabular}

yrs; 24 men, mean age 37 yrs) suffering from temporomandibular disorders. When the patients were asked to indicate if musculoskeletal discomfort/pain was present in 9 different areas defined on a rear view of the body, the regions with most "yes" answers were the neck and shoulders (66\% and 62\%, respectively) (Hagberg et al., 1994). These sites correspond to parts of the upper head, the neck, and parts of the upper back in our study, but also include the upper half of the upper arms. Our results also show the neck, shoulders, and upper back to be the most frequently involved regions outside of the head and face area. Hagberg and co-workers (1994) also reported a relatively high occurrence of pain in the low back, $61 \%$, as compared with $30 \%$ in our study. This can be explained by the larger extension of the low back area in the Swedish investigation. Pain was 

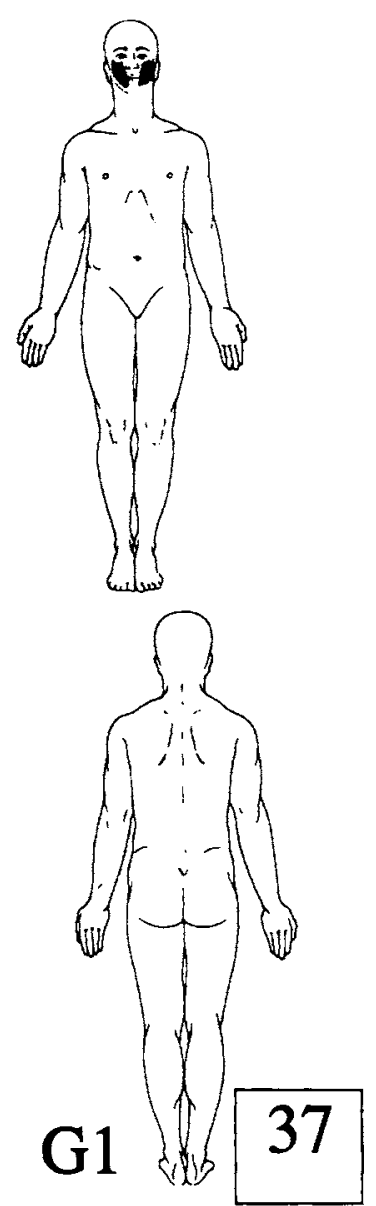
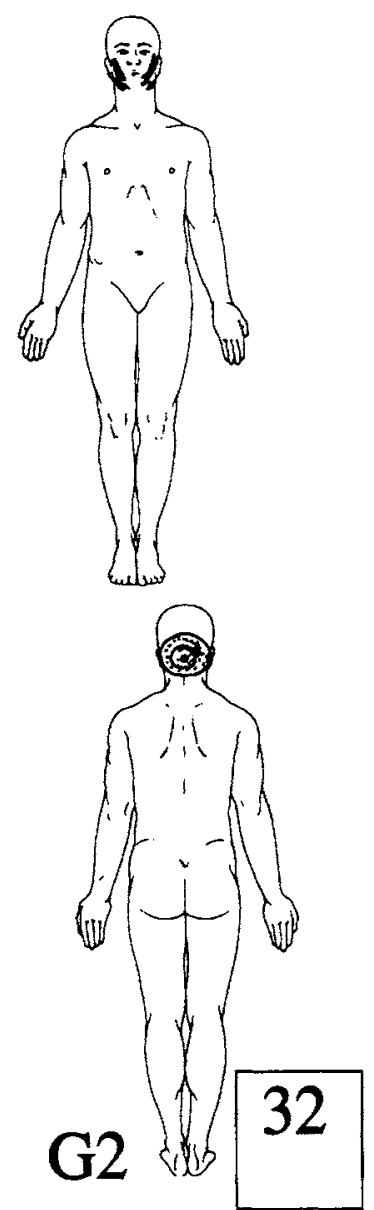
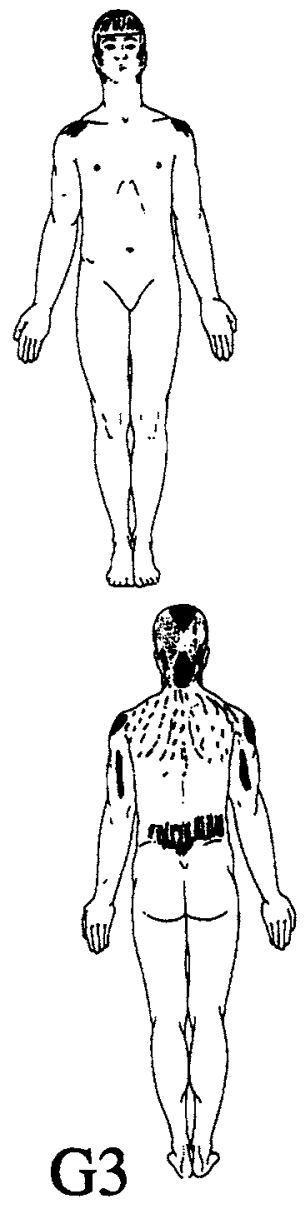
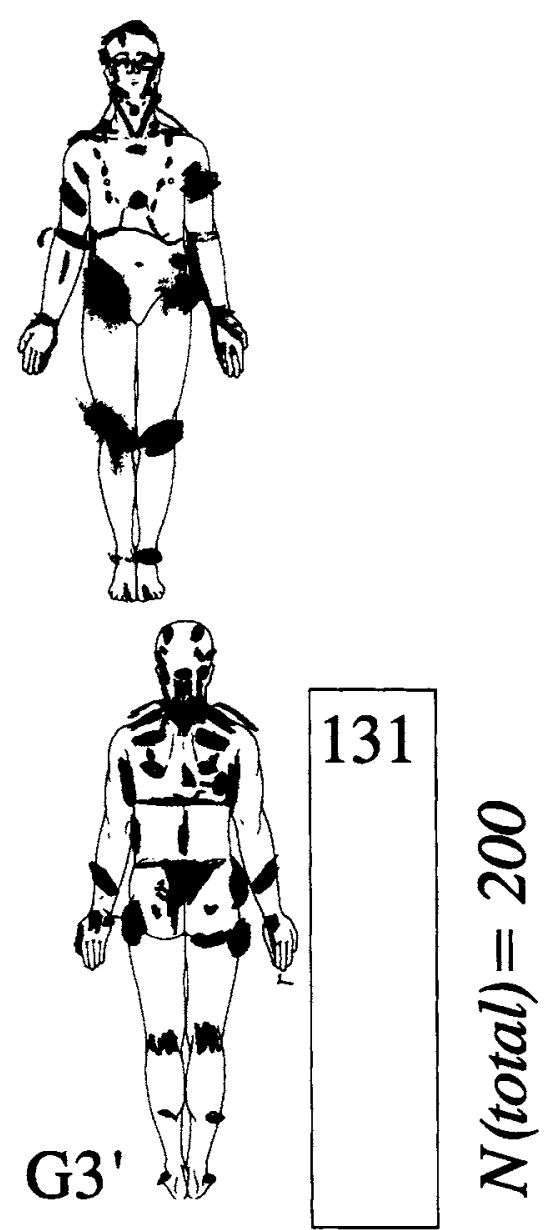

Figure 3. Typical pain drawings from members of patient subgroups G1 to G3. G3 represents the member of subgroup G3 with the most extensive pain drawing. The numbers in the bars indicate the number of patients in each subgroup.

most often bilateral in our sample; in only a minority of patients $(17.5 \%)$ was pain limited to one side of the body.

Based on the analysis of the drawings, pain reported by $83.5 \%$ of our PFP was characterized as spreading or radiating. This is not surprising, because Sessle et al. (1986) reported that there is a substantial convergence of afferent somatosensory input from different anatomical structures (e.g., masticatory muscles, tongue, neck, tooth pulps) at the level of neurons of the subnucleus caudalis of the spinal trigeminal nucleus. By trying to match spreading or radiating pain in the drawings with the corresponding word selection of the MGPQ, we observed a relatively low correspondence: Only $46 \%$ of the patients chose one of the corresponding words. There are several explanations for this poor correlation. First, our definition of "spreading" or "radiating" pain was quite arbitrary, i.e., we chose $4 \mathrm{~mm}$ solid dots or shaded areas as a cut-off point. In this respect, the classification of patients having this kind of pain was based solely on their drawings. A more direct instruction to indicate spreading/radiating pain may have resulted in a closer match. Another major point relates to the way the MGPQ is designed. Patients are explicitly asked not to circle more than one word in any group. Thus, patients experiencing piercing and radiating pain may have opted for the word "piercing", which would have precluded them from selecting "radiating". We are not able to tell if this was the case for all of the 45 patients who chose "penetrating" or "piercing", but if so, the degree of correspondence would increase to $73 \%$.

There is reason to believe that the methods used for scoring drawings will affect the results. Pain drawings can be analyzed by inspecting the pattern of the pain distribution (e.g., anatomically plausible or organic vs. implausible or inorganic pain pattern) (Palmer, 1949; Ransford et al., 1976; Gray et al., 1986; Udén and Landin, 1987; Hildebrandt et al., 1988; Udén et al., 1988; Arner et al., 1992; Mann et al., 1992; Russell et al., 1994; Ohnmeiss et al., 1995), or by determining the involvement of specific body sites in the drawing, usually with the help of a template ("pain site scoring system") (Toomey et al., 1983; Gray et al., 1986; Margolis et al., 1986; Gil et al., 1990; Allerbring and Hægerstam, 1993; Parker et al., 1995). In the first four analyses of our study, we followed the second approach. Although various scoring procedures have been described in the literature for that purpose, all use a division of the body surface into different anatomical regions.

Scoring divisions are not consistently applied from study to study. For example, using two different views of the body (front and rear), Sandmark and Nisell (1994) divided the 
Table 4. Relationship between the presence or absence of spreading or radiating pain in the drawings and choosing one of the words in word group 17 of the McGill Pain Questionnaire

\begin{tabular}{|c|c|c|c|c|c|c|c|}
\hline & & "Spreading" & "Radiating" & "Penetrating" & "Piercing" & No Word Chosen & Number of Cases \\
\hline $\begin{array}{r}\text { Spreading/ } \\
\text { Radiating }\end{array}$ & yes & 28 & 49 & 23 & 22 & 45 & 167 \\
\hline $\begin{array}{l}\text { Pain in } \\
\text { Drawing }\end{array}$ & no & 0 & 2 & 5 & 4 & 22 & 33 \\
\hline Number of & ases & 28 & 51 & 28 & 26 & 67 & 200 \\
\hline
\end{tabular}

body into 13 areas, whereas Gil et al. (1990) and Parker et al. (1995) distinguished 38 anatomical sites; Margolis et al. (1986) differentiated 45 body sections, Allerbring and Hægerstam (1993) specified 49 regions, and Vucetic et al. (1995) and Sikorski et al. (1996) identified 50 areas. Toomey and co-workers (1983) added two lateral views of the head/neck region and two intra-oral displays of the oral cavity to the front and rear views, for a total of 32 areas.

Variability also exists with regard to scoring procedures. One form of scoring consists of simply adding the number of pain sites included in the drawing (Toomey et al., 1983). Alternatively, in an attempt to compensate for differences in the extent of the body surface that the areas represent, Margolis and co-workers (1986) suggested assigning a weight to each. It is apparent, however, that the areas of the body defined by Toomey et al. (1983), Margolis et al. (1986), or Gil et al. (1990) cover a relatively large surface. Furthermore, it does not matter if a large part or only a small portion of a specific site is included in the drawing. In fact, by definition, an area is scored if any part of it is included in the drawing (Margolis et al., 1986). Hence, the final score may yield a distorted representation of the pain distribution, particularly when the number of grids included in the templates is low, as shown in a study carried out by Bryner (1994): The mean area included in 17 pain drawings (frontal and rear views) was $7.7 \%$ when 45 anatomical regions were distinguished, and decreased to $4.7 \%$ and $3.6 \%$, when the body was divided into 200 and 560 sections, respectively. When a computer-based approach that allowed for a 61,102section analysis was used, the value dropped to $2.3 \%$. Thus, dividing the body surface into almost 4000 "mini-regions", as was done in our study, has most certainly reduced the risk of overestimation of the amount of pain extant.

To our knowledge, the analysis of pain drawings according to the distribution of dermatomes is the first of its kind in the literature. In our sample, the involvement of dermatomes ranged from $1.5 \%$ (S4) to $60.0 \%$ (C2). It should be recognized that dermatomes are not separated from each other as sharply as illustrated in textbooks, but show a considerable amount of overlap (Marieb, 1995; Windhorst, 1996). Even with this cautionary note, it is apparent that the three clusters found in our study represent three clear and distinct types of pain distribution, namely, localized (G1), regional (G2), and widespread (G3) pain, thus corroborating previous empirical descriptions (Stohler, 1995).

The widespread pain distributions proved to be more persistent than the presentations with regional or restricted involvement of the trigeminal dermatomes. However, the mean age of the cluster members with regional and widespread pains was not different from the mean age of the subjects with local involvement. It is conceivable that different underlying pathological processes must be responsible for the variance in the spatial occurrence and persistence of pain. In that regard, the G1 cluster is very likely to embrace conditions such as TMJ arthralgia or masticatory myalgia -in the absence of additional pain sites in the body-whereas $\mathrm{G} 2$ includes the myofascial pain conditions, and G3 represents conditions that affect multiple sites (e.g., polyarthritides, fibromyalgia, or a combination of facial pain and non-related additional pain in parts of the body).

\section{Acknowledgments}

This project was partially supported by the Delta Dental Fund, NIH/NIDR RO1 12059-01, and NIH RO1-DE 8606-07.

\section{References}

Allerbring M, Hægerstam G (1993). Characteristics of patients with chronic idiopathic orofacial pain. A retrospective study. Acta Odontol Scand 51:53-58.

Arner M, Kopylov P, Holmberg J (1992). Pain drawing as an investigative tool in hand surgery. Scand J Plast Reconstr Surg Hand Surg 26:271-274.

Berry DC (1969). Mandibular dysfunction pain and chronic minor illness. Br Dent J 127:170-175.

Bertoft G (1996). Screening of medical and dental history of patients with chronic orofacial pain and discomfort using a questionnaire. Swed Dent J 20:95-106.

Blasberg B, Chalmers A (1989). Temporomandibular pain and dysfunction syndrome associated with generalized musculoskeletal pain: a retrospective study. I Rheumatol 16(Suppl 19):87-90.

Bryner P (1994). Extent measurement in localised low-back pain: a comparison of four methods. Pain 59:281-285.

Costen JB (1934). A syndrome of ear and sinus symptoms dependent upon disturbed function of the temporomandibular joint. Ann Otol Rhinol Laryngol 43:1-15.

Cummings GS, Routan JL (1987). Accuracy of the unassisted pain drawings by patients with chronic pain. I Orthopaed Sports Phys Ther 8:391-396.

Damon D, Massoth DL, F. DS, Wilson L, Harrison R, Ehrlich K (1994). Temporomandibular disorder (TMD) pain and pain site mappings (abstract). J Dent Res 73(Spec Iss): 186.

Eriksson PO, Lindman R, Stal P, Bengtsson A (1988). Symptoms and signs of mandibular dysfunction in primary fibromyalgia syndrome (PSF) patients. Swed Dent ) 12:141-149. 
Gelb H, Tarte J (1975). A two-year clinical dental evaluation of 200 cases of chronic headache: the craniocervicalmandibular syndrome. J Am Dent Assoc 91:1230-1236.

Gil KM, Phillips G, Abrams MR, Williams DA (1990). Pain drawings and sickle cell disease pain. Clin J Pain 6:105-109.

Gray RJ, Rothwell PS, Wastell DG (1986). An investigation of pain distribution in patients with temporomandibular joint pain dysfunction syndrome. J Dent 14:114-120.

Hagberg C (1991). General musculoskeletal complaints in a group of patients with craniomandibular disorders (CMD). A case control study. Swed Dent J 15:179-185.

Hagberg C, Hagberg M, Kopp S (1994). Musculoskeletal symptoms and psychosocial factors among patients with craniomandibular disorders. Acta Odontol Scand 52:170-177.

Heiberg AN, Helöe B, Krogstad BS (1978). The myofascial pain dysfunction: dental symptoms and psychological and muscular function. An overview. A preliminary study by team approach. Psychother Psychosom 30:81-97.

Hildebrandt J, Franz CE, Choroba-Mehnen B, Temme M (1988). The use of pain drawings in screening for psychological involvement in complaints of low-back pain. Spine 13:681-685.

Jensen MP, Karoly P (1992). Self-report scales and procedures for assessing pain in adults. In: Handbook of pain assessment. Jensen MP, Karoly P, editors. New York: The Guilford Press, pp. 135-151.

Keele KD (1948). The pain chart. Lancet ii:6-8.

Krause SJ, Tait RC, Margolis RB (1989). Pain distribution, intensity, and duration in patients with chronic pain. J Pain Symptom Manage 4:67-71.

Krogstad BS, Dahl BL, Eckersberg T, Ogaard B (1992). Sex differences in signs and symptoms from masticatory and other muscles in 19-year-old individuals. J Oral Rehabil 19:435-440.

Magnusson T, Carlsson GE (1978a). Comparison between two groups of patients in respect of headache and mandibular dysfunction. Swed Dent J 2:85-92.

Magnusson T, Carlsson GE (1978b). Recurrent headaches in relation to temporomandibularjoint pain-dysfunction. Acta Odontol Scand 36:333-338.

Mann NH 3rd, Brown MD, Enger I (1992). Expert performance in low-back disorder recognition using patient pain drawings. J Spinal Disord 5:254-259.

Mann NH 3rd, Brown MD, Hertz DB, Enger I, Tompkins J (1993). Initial-impression diagnosis using low-back pain patient pain drawings. Spine 18:41-53.

Margoles MS (1983). The pain chart: spatial properties of pain. In: Pain measurement and assessment. Margoles MS, editor. New York: Raven Press, pp. 215-225.

Margolis RB, Tait RC, Krause SJ (1986). A rating system for use with patient pain drawings. Pain 24:57-65.

Margolis RB, Chibnall JT, Tait RC (1988). Test-retest reliability of the pain drawing instrument. Pain 33:49-51.

Marieb EN (1995). Human anatomy and physiology. 3rd ed. Redwood City, CA: Benjamin/Cummings, p. 450.

McNeill TW, Sinkora G, Leavitt F (1986). Psychologic classification of low-back pain patients: a prognostic tool. Spine 11:955-959.

Melzack R (1975). The McGill Pain Questionnaire: major properties and scoring methods. Pain 1:277-299.

Ohnmeiss DD, Vanharanta H, Guyer RD (1995). The association between pain drawings and computed tomographic/ discographic pain responses. Spine 20:729-733.

Palmer H (1949). Pain charts. A description of a technique whereby functional pain may be diagnosed from organic pain. NZ Med J 48:187-213.

Parker H, Wood PL, Main CJ (1995). The use of the pain drawing as a screening measure to predict psychological distress in chronic low back pain. Spine 20:236-243.

Ransford AO, Cairns D, Mooney V (1976). The pain drawing as an aid to the psychologic evaluation of patients with lowback pain. Spine 1:127-134.

Russell MB, Iversen HK, Olesen J (1994). Improved description of the migraine aura by a diagnostic aura diary. Cephalalgia 14:107-117.

Sanderson PL, Wood PL (1993). Surgery for lumbar spine stenosis in old people. J Bone Joint Surg Br 75:393-397.

Sandmark H, Nisell R (1994). Measurement of pain among electricians with neck dysfunction. Scand J Rehabil Med 26:203-209.

Schokker RP, Hansson TL, Ansink BJ (1990). Craniomandibular disorders in patients with different types of headache. $J$ Craniomandib Disord 4:47-51.

Sessle BJ, Hu JW, Amano N, Zhong G (1986). Convergence of cutaneous, tooth pulp, visceral, neck and muscle afferents onto nociceptive and non-nociceptive neurons in trigeminal subnucleus caudalis (medullary dorsal horn) and its implications for referred pain. Pain 27:219-235.

Sikorski JM, Stampfer HG, Cole RM, Wheatley AE (1996). Psychological aspects of chronic low back pain. Aust NZ J Surg 66:294-297.

Solberg WK, Woo MW, Houston JB (1979). Prevalence of mandibular dysfunction in young adults. J Am Dent Assoc 98:25-34.

Stohler CS (1995). Clinical perspectives on masticatory and related muscle disorders. In: Temporomandibular disorders and related pain conditions. Stohler CS, editor. Seattle: IASP Press, pp. 3-29.

Takata K, Hirotani H (1995). Pain drawing in the evaluation of low back pain. Int Orthop 19:361-366.

Toomey TC, Gover VF, Jones BN (1983). Spatial distribution of pain: a descriptive characteristic of chronic pain. Pain 17:289-300.

Udén A, Landin LA (1987). Pain drawing and myelography in sciatic pain. Clin Orthop 216:124-130.

Udén A, Åström M, Bergenudd H (1988). Pain drawings in chronic back pain. Spine 13:389-392.

Vucetic N, Määttänen H, Svensson O (1995). Pain and pathology in lumbar disc hernia. Clin Orthop 320:65-72.

Wänman A, Agerberg G (1986). Headache and dysfunction of the masticatory system in adolescents. Cephalalgia 6:247-255 [published erratum appears in Cephalalgia 7(1):following 81, 1987].

Watters WC 3rd, Temple AP, Granberry M (1989). The use of dexamethasone in primary lumbar disc surgery. A prospective, randomized, double-blind study. Spine 14:440-442.

Wigers SH, Stiles TC, Vogel PA (1996). Effects of aerobic exercise versus stress management treatment in fibromyalgia. A 4.5 year prospective study. Scand J Rheumatol 25:77-86.

Windhorst $U$ (1996). Central projections of cutaneous and enteroceptive senses. In: Comprehensive human physiology. Windhorst U, editor. Berlin: Springer, pp. 623-646. 